\title{
Correlation between Structural, Infrared and Nuclear Quadrupole Resonance Data of Iodates*
}

\author{
A. M. Petrosyan and V. A. Shishkin \\ Department of Physics Yerevan State University, Alex Manoogian str. 1, Yerevan 375049, Armenia \\ Z. Naturforsch. 51a, 667-671 (1996); received January 30, 1996 \begin{abstract}
which contain the $\mathrm{I}_{2} \mathrm{O}_{5}$ group are reported. Based in this, the results for several iodates that contain organic cations are considered.
\end{abstract} \\ The peculiarities of the structure and the IR and NQR spectra of acid iodates and pyroiodates
}

Key words: Iodates, NQR and IR spectroscopy, Structure.

\section{Introduction}

After two papers with incorrect data on NQR of $\mathrm{I}_{2} \mathrm{O}_{5}[1,2]$, numerous papers on various classes of iodates were stimulated by three papers on iodine-127 NQR of $\alpha-\mathrm{HIO}_{3}[3-5]$. Based on NQR data, Herlach [6] indicated that none of the alkaline metal iodates have a perovskite structure, as was confirmed by further structural studies on iodates. At present we know the structure, infrared spectra and NQR of (i) simple iodates of metals having various valencies (ii) complicated iodates whose chromatoiodate $\mathrm{CrIO}_{6}$ type heteroions represent $\mathrm{CrO}_{4}$ tetrahedra which are connected with the $\mathrm{IO}_{3}$ group via oxygen bridges, (iii) complex iodates $\mathrm{M}^{\mathrm{I}} \mathrm{M}^{\mathrm{IV}}\left(\mathrm{IO}_{3}\right)_{6}$, where $\mathrm{M}^{\mathrm{I}}$ is an alkaline metal, $\mathrm{NH}_{4}$ or $\mathrm{H}$, and $\mathrm{M}^{\mathrm{IV}}$ is $\mathrm{Sn}, \mathrm{Ge}, \mathrm{Ti}, \mathrm{Zr}, \mathrm{Pb}$ or $\mathrm{Mn}$, (iv) acid iodates that contain the $\mathrm{HIO}_{3}$ group, and (v) pyroiodates that contain the groups $\mathrm{I}_{2} \mathrm{O}_{5}$ and $\mathrm{IO}_{3}$. We shall consider the peculiarities of these crystals and their correlation with NQR data (Table 1) and IR spectra, and then we shall discuss based on their NQR data, the peculiarities of the structures of several iodates with organic cations.

\section{Correlation of Structure and NQR and IR Spectra Data}

The iodate group is a triangular pyramid with an iodine atom in the vertex and three oxygen atoms in the base. The distance of $\mathrm{I}-\mathrm{O}$ is approximately $1.81 \AA$, and the angles at the vertex are ca. $100^{\circ}$. The $\mathrm{I}-\mathrm{O}$ distance is greater than the double bond length $I=\mathrm{O}$,

\footnotetext{
* Presented at the XIIIth International Symposium on Nuclear Quadrupole Interactions, Providence, Rhode Island, USA, July 23-28, 1995.
}

Reprint requests to Dr. A. M. Petrosyan. which equals $1.78 \AA$, and smaller than the single bond length $(1.99 \AA)$. The sum of van der Waals radii of iodine and oxygen is $3.5 \AA$. In crystal structures of iodates, besides these three closest atoms the iodine atom is surrounded by another three (rarely with two of four) oxygen atoms with an I-O distance of 2.6 up to $3.2 \AA$. This causes a distorted octahedral environment of iodine. In a pure form this occurs in case of $\mathrm{RbIO}_{3}$ [7] where the three closest $\mathrm{I}-\mathrm{O}$ bonds measure 1.807 (3) $\AA$, the three weaker I ... O bonds 2.753 (3) $\AA$, and the apex angles $\mathrm{O}-\mathrm{I}-\mathrm{O} 99.63^{\circ}$. In $\alpha-\mathrm{LiIO}_{3}$ the situation is similar [8].

Axial symmetry of the $\mathrm{IO}_{3}$ group brings about a zero EFG tensor asymmetry parameter $\eta$ on iodine (see Table 1 for $\mathrm{RbIO}_{3}$ and [9] for $\alpha-\mathrm{LiIO}_{3}$ ).

A slight deviation of $\eta$ from zero for $\alpha-\mathrm{LiIO}_{3}$ [10] may be explained by the formation of $\mathrm{Li}_{1-x} \mathrm{H}_{x} \mathrm{IO}_{3}$ solid solutions during $\alpha-\mathrm{LiIO}_{3}$ growth from acid solutions [11].

Close axial symmetry and hence small values of $\eta$ are observed for other alkaline metal- and ammonium iodates. The quadrupole coupling constant of alkaline metal iodates is approximately $1000 \mathrm{MHz}$. A weak $(<5 \%)$ but regular decrease at the transition from $\mathrm{Li}$ to Cs is observed, which demonstrates the decrease of ionic contribution with increasing ionic radius and a decrease of the cation polarizing capabilities. This shows that the EFG is mainly due to covalent iodineoxygen bonds $[9,12]$.

Various iodate group interactions may cause a departure of a regular pyramid. Such interactions can be (i) stronger bonds of the iodate group oxygen with the metal, (ii) even stronger bonds $\mathrm{O}$...I, the lengths of which can vary between 2.2 and $2.5 \AA$ (these bonds can be considered as intermediate between first and second coordination spheres [13]), (iii) covalent bonds, 
which can be carried out via oxygen as well as hydrogen bonds observed in acid iodates and crystalline hydrates. These interactions appear in changes of the asymmetry parameter and quadrupole coupling constant. Thus, when going from alkaline metal iodates to metal iodates with higher valencies, the bond covalency between the oxygen and metal increases, and this causes an increase of both the asymmetry parameter and quadrupole coupling constant. A correlation between these values and metal valencies ' $n$ ' takes place $[9,14]$ :

$$
\begin{aligned}
\eta & =0.111 n-0.095, \\
e Q q(\mathrm{MHz}) & =23.24 n+974.57 .
\end{aligned}
$$

The great value of one of the two non equivalent iodine atoms in the $\mathrm{AgIO}_{3}$ structure asymmetry parameter is somehow unexpected (see Table 1).

The explanation is found in a peculiarity of the $\mathrm{AgIO}_{3}$ structure [15]. Normal I(1)-O and I (1) ... O is observed in one of the two non equivalent iodate groups $(1.78-1.81 \AA)$ and $(2.74-2.99 \AA)$ respectively, while in the other one at usual $\mathrm{I}(2) \ldots \mathrm{O}$ bonds $(2.71-2.77 \AA)$ somewhat unusual bonds $\mathrm{I}(2)-\mathrm{O}(6)$ $(1.80 \AA), \mathrm{I}(2)-\mathrm{O}(1)(1.85 \AA)$ and $\mathrm{I}(2)-\mathrm{O}(2)(1.85 \AA)$ are observed. Such a lengthening is due to the existance of short contacts of two oxygen atoms of the $\mathrm{I}(2) \mathrm{O}_{3}$ group with silver ions $\mathrm{Ag}(1)-\mathrm{O}(1)(2.38 \AA)$ and $\mathrm{Ag}(2)-\mathrm{O}(3)$ (2.37 $\AA$ ). While the average distance from other five oxygen atoms of each silver ion is $2.60 \AA$. Thus, a strong deviation from the correlation (1) may indicate unusual bonds, which causes the distortion of the iodate group.

Even grater distortions of the iodate group are observed on covalent bond formation with oxygen atoms. The iodic acid $\mathrm{HIO}_{3}$ can serve as an example. The non-equivalent $\mathrm{I}-\mathrm{OH}$ bond length for $\alpha-\mathrm{HIO}_{3}$ is $1.90 \AA$, and for the other two $1.79 \AA$. Though the $\mathrm{I}-\mathrm{OH}$ bond is much longer than the other two, due to the hydrogen bonding this bond is still shorter than the single bond. It is interesting to note that in acid iodates the $\mathrm{I}-\mathrm{OH}$ bond may be both longer and shorter than in pure $\mathrm{HIO}_{3}$, depending on the strength of the hydrogen bond and other structure peculiarities.

The structure of acid sulphate-iodate of potassium has been determined by X-ray diffraction [16]. Observing an $\mathrm{I}-\mathrm{O}$ bond length of $1.90 \AA$ in the iodate group, the authors [16] concluded that this group represents an $\mathrm{HIO}_{3}$ molecular and suggested the formula $\mathrm{HIO}_{3} \cdot \mathrm{K}_{2} \mathrm{SO}_{4}$. The structure of this crystal has
Table 1. Data on iodate iodine-127 NQR of various com-

\begin{tabular}{|c|c|c|c|c|c|}
\hline Compound & $T / \mathrm{K}$ & $\begin{array}{l}v_{1} \\
\mathrm{MHz}\end{array}$ & $\begin{array}{l}v_{2} \\
\mathrm{MHz}\end{array}$ & $\eta$ & $\begin{array}{l}e Q q_{z z} \\
\mathrm{MHz}\end{array}$ \\
\hline $\mathrm{RbIO}_{3}$ & 300 & 145.44 & 290.88 & 0.0000 & 969.60 \\
\hline $\mathrm{NH}_{4} \mathrm{IO}_{3}$ & 300 & 147.24 & 294.41 & 0.0135 & 981.40 \\
\hline $\mathrm{AgIO}_{3}$ & & $\begin{array}{l}148.31 \\
15358\end{array}$ & $\begin{array}{l}291.96 \\
30673\end{array}$ & 0.1112 & $\begin{array}{r}975.64 \\
102266\end{array}$ \\
\hline$\alpha-\mathrm{HIO}_{3}$ & 77 & 203.12 & 330.84 & 0.4337 & 1141.03 \\
\hline$\beta-\mathrm{HIO}_{3}^{3}$ & 77 & 192.88 & 326.40 & 0.3849 & 1118.30 \\
\hline \multirow{5}{*}{$\begin{array}{l}\mathrm{HIO}_{3} \cdot \mathrm{K}_{2} \mathrm{SO}_{4} \\
\beta-\mathrm{KIO}_{3} \cdot \mathrm{HIO}_{3}\end{array}$} & 300 & 236.44 & 340.30 & 0.5796 & 1199.94 \\
\hline & 300 & 146.97 & 289.08 & 0.1142 & 966.14 \\
\hline & & 154.77 & 305.87 & 0.0964 & 1021.48 \\
\hline & & 193.06 & 304.45 & 0.4732 & 1055.99 \\
\hline & & 193.40 & 315.40 & 0.4322 & 1087.54 \\
\hline \multirow{2}{*}{$\mathrm{KIO}_{3} \cdot \mathrm{HIO}_{3} \cdot \mathrm{KCl}$} & 300 & 148.40 & 291.50 & 0.1188 & 974.44 \\
\hline & & 19474 & 31443 & $\begin{array}{l}0.5682 \\
0.4445\end{array}$ & 1065.07 \\
\hline $\mathrm{K}_{2}\left[\mathrm{Ge}\left(\mathrm{IO}_{3}\right)_{6}\right]$ & 293 & 19296 & 310.05 & $\begin{array}{l}0.4445 \\
0.4505\end{array}$ & $\begin{array}{l}1086.09 \\
1071.87\end{array}$ \\
\hline \multirow{5}{*}{$\begin{array}{l}\mathrm{KCrIO}_{6} \\
\mathrm{I}_{2} \mathrm{O}_{5}\end{array}$} & 77 & 205.34 & 313.24 & 0.5125 & 1092.93 \\
\hline & 77 & 217.75 & 329.02 & 0.5236 & 1149.95 \\
\hline & & 249.03 & 357.58 & 0.5822 & 1261.42 \\
\hline & 300 & 216.53 & 323.47 & 0.5367 & 1132.84 \\
\hline & & & & & 1226.95 \\
\hline \multirow[t]{6}{*}{$\mathrm{HIO}_{3} \cdot \mathrm{I}_{2} \mathrm{O}_{5}$} & 77 & 178.03 & 316.35 & 0.3172 & 1074.91 \\
\hline & & 213.55 & 308.24 & 0.5763 & 1086.31 \\
\hline & & 221.35 & 318.57 & 0.5796 & 1123.32 \\
\hline & 300 & 177.46 & 312.02 & 0.3325 & 1062.11 \\
\hline & & 210.00 & 303.30 & 0.5756 & 1068.79 \\
\hline & & 221.98 & 313.42 & 0.6014 & 1109.04 \\
\hline \multirow{3}{*}{$\mathrm{RbIO}_{3} \cdot \mathrm{I}_{2} \mathrm{O}_{5}$} & 77 & 155.90 & 301.70 & 0.1616 & 1010.93 \\
\hline & & 252.10 & 319.03 & 0.7247 & 1152.35 \\
\hline & & & & 0.7282 & 1172.85 \\
\hline \multirow{2}{*}{$\mathrm{KIO}_{3} \cdot \mathrm{I}_{2} \mathrm{O}_{5}$} & 77 & 162.60 & 308.15 & 0.2084 & 1036.03 \\
\hline & & 259.75 & 319.80 & 0.7557 & 1161.22 \\
\hline \multirow{4}{*}{$2 \mathrm{KIO}_{3} \cdot \mathrm{I}_{2} \mathrm{O}_{5}$} & 77 & 204.02 & 331.15 & 0.1321 & 1199.93 \\
\hline & & $\begin{array}{l}100.02 \\
166.45\end{array}$ & 305.35 & 0.2644 & $\begin{array}{l}1019.84 \\
1033.69\end{array}$ \\
\hline & & & 319.90 & 0.6903 & 1148.82 \\
\hline & & 266.60 & 327.25 & 0.7592 & 1188.95 \\
\hline
\end{tabular}
pounds.

been determined once again in [17]. For the iodate group the following bond lengths have been obtained:

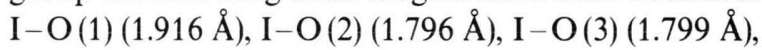
which undoubtedly is $\mathrm{HIO}_{3}$. Besides, there exists a short contact between iodine atom and one of the sulphate group oxygen atoms I...O (4) (2.495 $\AA$ ) (while the bond $\mathrm{S}-\mathrm{O}(4)$ is simultaneously lengthening). This was the basis for the author of [17] to suggest the formula $\mathrm{K}_{4} \mathrm{H}_{2}\left(\mathrm{I}_{2} \mathrm{~S}_{2} \mathrm{O}_{14}\right)$, which from our point of view is not as clear. The $\mathrm{I}-\mathrm{O}$ bond lengths obtained in [17] are in better agreement with the NQR data for $\mathrm{HIO}_{3} \cdot \mathrm{K}_{2} \mathrm{SO}_{4}$ (see Table 1), as the values of $\eta$ and $e Q q$ are maximal for this crystal among all those obtained for $\mathrm{HIO}_{3}$ now in use. This shows the weakness of the hydrogen bond and maximal distortion of the $\mathrm{HIO}_{3}$ group (see also [18], where the spectroscopic and thermal behaviour of this crystal has been studied). 
From the aforesaid it can be seen that the bond length is sufficiently sensitive and reflects the state of the iodate group. In X-ray structural works, in the presence of iodine atom it is difficult to localize the hydrogen atom. The bond lengths in the iodate group are the bases for $\mathrm{IO}_{3}, \mathrm{HIO}_{3}$ and hydrogen bond recognitions [13]. Values of $e Q q$ for the $\mathrm{IO}_{3}^{-}$group are usually lower than $1050 \mathrm{MHz}$, whereas for the covalently bonded $\mathrm{IO}_{3}$ group ( $\mathrm{HIO}_{3}$ etc.) they are higher than $1050 \mathrm{MHz}$. The asymmetry parameter $\eta$ is more sensitive. This is why the correlation between $\eta$ and nonequivalent (the longest bond lengths $D(\mathrm{I}-\mathrm{O})$ seems well grounded [19]:

$$
D(A)=0.2103 \eta+1.812 \text {. }
$$

There exists another approach to connecting $\eta$ and $e Q q$ with iodate group distortion [20,21], namely with variation of $\mathrm{IO}_{3}$ apex angles. In [10] an attempt has been made to justify this connecting. Without denying the role of angle variation, we note the inconvenience and insufficient justification of this approach, that may lead to incorrect conclusions. A correlation between the $\mathrm{I}-\mathrm{O}$ stretching frequencies and the lengths of these bonds [22] was also established, which can be expressed by the relation [23]

$$
v\left(\mathrm{~cm}^{-1}\right)=3256-1380 D(A) .
$$

From (2) and (3) a correlation between the asymmetry parameter and the stretching frequency of the longest bond can be obtained:

$$
v\left(\mathrm{~cm}^{-1}\right)=755-290 \eta .
$$

From the example of $\beta-\mathrm{KIO}_{3} \cdot \mathrm{HIO}_{3}$, the sensitivity and efficiency of the NQR method in revealing fine peculiarities of hydrogen bond can be seen. Insufficient accuracy of the X-ray experiment on the structure of $\beta-\mathrm{KIO}_{3} \cdot \mathrm{HIO}_{3}$ [24] lead the authors of [25] to the conclusion that at room temperature there exist dimers $\mathrm{H}\left(\mathrm{IO}_{3}\right)_{2}$ with $\overline{1}$ symmetry, similar to that obtained for $\alpha-\mathrm{KH}\left(\mathrm{IO}_{3}\right)_{2}$. However, the NQR data show that despite the strong hydrogen bond $\mathrm{IO}_{3} \ldots \mathrm{HIO}_{3}$ [26] one can easily distinct $\mathrm{IO}_{3}$ and $\mathrm{HIO}_{3}$ groups, and hence there are no dimers with $\overline{1}$ symmetry. This indicated the necessity of another more accurate determination of the $\beta$-modification structure, which was carried out in [27]. This neutron diffraction study of $\beta-\mathrm{KIO}_{3} \cdot \mathrm{HIO}_{3}$ reveals $\mathrm{IO}_{3} \ldots \mathrm{HIO}_{3}$ grouping with nonsymmetric hydrogen bond in full accordance with the NQR data.

One other interesting example of acid iodates is the potassium biiodate-chloride [28]. According to NQR data it may be concluded that an $\mathrm{HIO}_{3}$ group $(\eta=0.5682)$ and a sufficiently distorted $\mathrm{IO}_{3}$ group $(\eta=0.1188)$ exist. However, here the distortion of the $\mathrm{IO}_{3}$ group is not so much due to hydrogen bond (in this case the same values of $\eta$ for $\mathrm{HIO}_{3}$ as in $\beta-\mathrm{KIO}_{3} \cdot \mathrm{HIO}_{3}$ could be expected), than due to strong $\mathrm{I}$... O $\mathrm{O}$ bond with $2.536 \AA$ length between the iodine $\mathrm{HIO}_{3}$ and oxygen $\mathrm{IO}_{3}$ group, which leads to appropriate lengthening of the $\mathrm{I}-\mathrm{O}$ bond in $\mathrm{IO}_{3}$ [29].

In Table 1, NQR data for $\mathrm{K}_{2} \mathrm{Ge}\left(\mathrm{IO}_{3}\right)_{6}$ are given as an example of alkaline metal hexaiodatometalate $\mathrm{M}^{\mathrm{I}} \mathrm{M}^{\mathrm{IV}}\left(\mathrm{IO}_{3}\right)_{6}$, where $\mathrm{M}^{\mathrm{I}}$ is alkaline metal, $\mathrm{NH}_{4}$ or $\mathrm{H}$ and $\mathrm{M}^{\mathrm{IV}}$ is $\mathrm{Sn}, \mathrm{Ge}, \mathrm{Ti}, \mathrm{Zr}, \mathrm{Pb}$ or $\mathrm{Mn}$. The crystal structure of $\mathrm{K}_{2} \mathrm{Ge}\left(\mathrm{IO}_{3}\right)_{6}$ has been determined [30] from $\mathrm{M}^{\mathrm{I}} \mathrm{M}^{\mathrm{IV}}\left(\mathrm{IO}_{3}\right)_{6}$ isomorphous compounds [31]. In the $\mathrm{Ge}\left(\mathrm{IO}_{3}\right)_{6}^{--}$ion, the central $\mathrm{Ge}$ atom is surrounded by six oxygen atoms at equal $1.901 \AA$ distances which form a regular octahedron. At two usual bonds $1.796 \AA$ and $1.801 \AA$, the iodate groups have one longer bond $1.861 \AA$ due to covalent bond formation between one oxygen atom with the central $\mathrm{Ge}$ atom. All the iodate groups are crystallographically equivalent. In accordance with structural data, on each transition $\left(v_{1}\right.$ and $\left.v_{2}\right)$ only one line is observed, the values $\eta$ and $e Q q$ of which correspond to the appropriate parameters of $\alpha-\mathrm{HIO}_{3}$.

The $\mathrm{CrIO}_{6}^{-}$-chromatoiodate heteroion represents a $\mathrm{CrO}_{4}$ tetrahedron and an $\mathrm{IO}_{3}$ group, covalently connected via a common bridge oxygen atom $\mathrm{O}_{3} \mathrm{Cr}-\mathrm{O}-\mathrm{IO}_{2}$ [32]. The $\mathrm{I}-\mathrm{O}$ bond length with the bridge oxygen $(1.899 \AA)$ longer than the two other ones ( $1.742 \AA$ and $1.787 \AA$ ), and the iodate group represents a distorted covalently bonded grouping. The values $\eta$ and $e Q q$ of Table 1 could be expected on the basis of correlations (1) and (2).

The $\mathrm{I}_{2} \mathrm{O}_{5}$ iodic anhydride [33] has a structure somewhat remainding that of the chromatoiodate ion. Here two iodate groups are connected via the common oxygen atom, the bonds of which are close to the single bond $\mathrm{O}_{2} \mathrm{I}-\mathrm{O}-\mathrm{IO}_{2}$. The iodine atoms of this group, however, are crystallographically inequivalent. One of the iodine atoms has an additional intrachain bond I... O, whereas the other one has also an interchain bond $\mathrm{I} \ldots \mathrm{O}$. In the $\mathrm{I}_{2} \mathrm{O}_{5}$ structure, the shortest $\mathrm{I} \ldots \mathrm{O}$ bond length is only $2.23 \AA$. As it was expected, the asymmetry parameters of $\mathrm{I}_{2} \mathrm{O}_{5}$ are very high (Table 1). Appropriate pairs of line $v_{1}$ and $v_{2}$ are determined by the two-frequency method. In the structure of anhydro-iodic acid, $\mathrm{HIO}_{3} \cdot \mathrm{I}_{2} \mathrm{O}_{5}\left(\mathrm{HI}_{3} \mathrm{O}_{8}\right)$ [34], it was found 
that the groups $\mathrm{I}_{2} \mathrm{O}_{5}$ and $\mathrm{HIO}_{3}$ are hydrogen bonded with each other. Thus, in the NQR spectra, two lines on each transition could be expected, the asymmetry parameters of which are characteristic for the $\mathrm{I}_{2} \mathrm{O}_{5}$ group $(\eta=0.5756$ and $\eta=0.6014)$, and one line of which is characteristic for $\mathrm{HIO}_{3}$ group $(\eta=0.3325)$. The checking by the two-frequency method revealed the "mixing up" of two lines in the $\mathrm{HIO}_{3} \cdot \mathrm{I}_{2} \mathrm{O}_{5} \mathrm{NQR}$ spectra (see Table 1). We have listed on such a possibility in [35]. $\mathrm{HI}_{3} \mathrm{O}_{8}$ full NQR spectra have been obtained by the authors of [20] independently of us [19, $35,36]$. However, from our point of view these authors, without having the full $\mathrm{I}_{2} \mathrm{O}_{5} \mathrm{NQR}$ spectra and assuming a connection between $e Q q$ and the apex angles of the pyramid, have assigned incorrectly the line with $221 \mathrm{MHz}$ frequency to the $\mathrm{HIO}_{3}$ group, and lines with $178 \mathrm{MHz}$ and $213 \mathrm{MHz}$ frequencies to the $\mathrm{I}_{2} \mathrm{O}_{5}$ group.

The structures of potassium and rubidium pyroiodates given in Table 1 are unknown. Nevertheless, on the basis of NQR data we may find their structure. The $\mathrm{I}_{2} \mathrm{O}_{5}$ groups in these compounds approach maximal distortion. The bond lengths $\mathrm{I}-\mathrm{O}-\mathrm{I}$ in the bridges approach the maximum for single $\mathrm{I}-\mathrm{O}$ bonds $(1.99 \AA)$. The asymmetry parameter, that corresponds to this length (on (2) $\eta \sim 0.85$ ) is close to those observed in these compounds. At the same time we have an essential value of $\eta$ for the $\mathrm{IO}_{3}$ group. As far as very short bonds between alkaline metal and the $\mathrm{IO}_{3}$ group oxygen are unprobable, we can suppose very short $\mathrm{O} \ldots \mathrm{I}$ bonds between the $\mathrm{IO}_{3}$ group oxygen and the $\mathrm{I}_{2} \mathrm{O}_{5}$ group iodine atoms. Thus, $\mathrm{KIO}_{3} \cdot \mathrm{I}_{2} \mathrm{O}_{5}$ and $\mathrm{RbIO}_{3} \cdot \mathrm{I}_{2} \mathrm{O}_{5}$ could be formally considered as salts of anhydro-iodic acid $\mathrm{HI}_{3} \mathrm{O}_{8}$, where the $\mathrm{I}_{3} \mathrm{O}_{8}^{-}$ion is expressed as a unit. Similar conclusion can be made in connection with $2 \mathrm{KIO}_{3} \cdot \mathrm{I}_{2} \mathrm{O}_{5}$ when considering $\mathrm{K}_{2} \mathrm{I}_{4} \mathrm{O}_{11}$.

\section{On Structure of Several Iodates with Organic Cations}

In Table 2 several iodates with organic cations [23, 37-40] are given, where only the crystal structure of guanidinium iodate $\mathrm{C}\left(\mathrm{NH}_{2}\right)_{3} \mathrm{IO}_{3}$ is known [41]. Values of $\eta$ and $e Q q$ are calculated from an equation obtained by A. F. Volkov [42] (see also [43]) on the basis of NQR frequency measurements:

$$
\frac{\left(1-\eta^{2}\right)^{2}}{\left(3+\eta^{2}\right)^{3}}=\frac{343}{10800} \cdot \frac{[(a-1)(a+2)(2 a+1)]^{2}}{\left(a^{2}+a+1\right)^{3}},
$$

$$
e Q q_{z z}=20 v_{1} \sqrt{\frac{a^{2}+a+1}{21\left(3+\eta^{2}\right)}}, \quad \text { where } a=\frac{v_{2}}{v_{1}} .
$$

Tetramethylammonium (TMA) iodate is characterised by a rather greater than ammonium iodate asymmetry parameter. Nevertheless, the value of $e Q q$ is smaller. This could be expected from the common behaviour of $e Q q$ decrease while encreasing the cation radius in the series of alkaline metals [9].

TMA iodate dihydrate has an even greater asymmetry parameter than the anhydrous one at approximately the same value of $e Q q$, which apparently is connected with additional distortion of the iodate group due to hydrogen bonds with water molecules. In the range of $77 \mathrm{~K}$ up to room temperature, no phase transition is observed, however, in anhydrous TMA iodate the authors of [44] found a phase transition near $210^{\circ} \mathrm{C}$.

In acid TMA iodate the $\mathrm{HIO}_{3}$ group is characterised by a sufficiently great asymmetry parameter $(\eta=0.5245)$, whereas the $\mathrm{IO}_{3}$ group is characterised by relatively lower values $(\eta=0.0576)$, which allows

Table 2. Data on iodate iodine-127 NQR of compounds with organic cations, the structures of which are mainly un-

\begin{tabular}{|c|c|c|c|c|c|}
\hline Compound & $T / \mathrm{K}$ & $\begin{array}{l}v_{1} \\
\mathrm{MHz}\end{array}$ & $v_{2}{ }^{2} \mathrm{~Hz}$ & $\eta$ & $\begin{array}{l}e Q q_{z z} \\
\mathrm{MHz}\end{array}$ \\
\hline \multirow[t]{2}{*}{$\mathrm{N}\left(\mathrm{CH}_{3}\right)_{4} \mathrm{IO}_{3}$} & 77 & 146.72 & 297.50 & 0.0885 & 969.87 \\
\hline & 300 & 140.28 & 278.09 & 0.0829 & \\
\hline \multirow[t]{2}{*}{$\mathrm{N}\left(\mathrm{CH}_{3}\right)_{4} \mathrm{IO}_{3} \cdot 2 \mathrm{H}_{2} \mathrm{O}$} & 77 & 149.18 & 290.75 & 0.1427 & 973.16 \\
\hline & 300 & 141.22 & 276.33 & 0.1311 & 924.29 \\
\hline \multirow{5}{*}{$\begin{array}{l}\mathrm{N}\left(\mathrm{CH}_{3}\right)_{4} \mathrm{IO}_{3} \cdot \mathrm{HIO}_{3} \\
\mathrm{H}_{2} \mathrm{O} \\
\left(\mathrm{NH}_{2}\right)_{2} \mathrm{CO} \cdot \mathrm{HIO}_{3}\end{array}$} & 77 & 150.79 & 300.29 & 0.0576 & 1001.64 \\
\hline & 77 & $\begin{array}{l}202.28 \\
158.28\end{array}$ & $\begin{array}{l}305.42 \\
311.64\end{array}$ & $\begin{array}{l}0.5245 \\
0.1107\end{array}$ & $\begin{array}{l}1067.61 \\
1041.37\end{array}$ \\
\hline & & 159.20 & 312.86 & 0.1172 & 1045.76 \\
\hline & & 160.29 & & 0.0518 & 1065.48 \\
\hline & & 2.51 & 309.75 & 0.1965 & 1040.45 \\
\hline \multirow{4}{*}{$\mathrm{C}\left(\mathrm{NH}_{2}\right)_{3} \mathrm{IO}_{3}$} & 77 & 156.08 & 306.10 & 0.1240 & 1023.49 \\
\hline & & 160.52 & 314.60 & 0.126 & 1052.03 \\
\hline & 298 & 152.12 & 298.40 & 0.1 & 997.71 \\
\hline & & & & & 1025.66 \\
\hline \multirow{2}{*}{$\alpha-\mathrm{En} \cdot 2 \mathrm{HIO}_{3}$} & 77 & 0.72 & & 0.1 & 990.10 \\
\hline & 293 & & & & 963.06 \\
\hline \multirow[t]{2}{*}{$\beta$-En $\cdot 2 \mathrm{HIO}_{3}$} & 77 & 149.81 & 297.82 & 0.0684 & 993.67 \\
\hline & 293 & 146.12 & 289.90 & 0.0790 & 967.56 \\
\hline \multirow[t]{3}{*}{$\mathrm{En} \cdot 3 \mathrm{HIO}_{3}$} & 77 & 155.75 & 307.68 & 0.0980 & 1027.60 \\
\hline & & 161.00 & 309.64 & 0.1751 & 1039.13 \\
\hline & & 3.13 & & 0.5681 & 1141 \\
\hline \multirow[t]{6}{*}{$\mathrm{En} \cdot 6 \mathrm{HIO}_{3}$} & 77 & 159.95 & 312.76 & 0.1332 & 1046.26 \\
\hline & & 197.32 & 316.10 & 0.4542 & 1093.36 \\
\hline & & 222.10 & 325.37 & 0.5593 & 1143.60 \\
\hline & 293 & 156.72 & 307.64 & 0.1210 & 1028.49 \\
\hline & & 194.24 & 309. & 0.45 & 1072.86 \\
\hline & & 216.71 & 317.66 & 0.5587 & 1116.36 \\
\hline
\end{tabular}
known.

En - ethylendiamine $\left(\mathrm{H}_{2} \mathrm{NCH}_{2} \mathrm{CH}_{2} \mathrm{NH}_{2}\right)$ 
us to suppose that the hydrogen bond is relatively weak and short I...O contacts are absent.

There are four inequivalent iodine atoms in the unit cell of hydroiodate of urea, none of which enters the $\mathrm{HIO}_{3}$ group. On proton transition from the $\mathrm{HIO}_{3}$ group to urea, uronium cation formation can be concluded. The mean values of $\eta$ and $e Q q$ for uronium iodate are close to of those of the guanidinium iodate.

Both iodate groups in $\alpha$ - and $\beta$-En $\cdot 2 \mathrm{HIO}_{3}$ are equivalent, and the values of $\eta$ and $e Q q$ are typical for the $\mathrm{IO}_{3}$ group, and not for the $\mathrm{HIO}_{3}$ group, which certifies on ethylendiamine protonation with ethylendiammonium iodate formation. The difference between the $\alpha$ and $\beta$ modifications are apparently due to different conformations of ethylendiammonium [23].

Addition of one more $\mathrm{HIO}_{3}$ molecule in En $\cdot 3 \mathrm{HIO}_{3}$ causes the formation of a hydrogen bond

[1] K. Shimomura, T. Kushida, N. Inoue, and Y. Imaeda, J. Chem. Phys. 22, 350 (1954).

[2] S. Kojima, T. Tsukada, S. Ogawa, and A. Shimauchi, J. Chem. Phys. 23, 1963 (1955).

[3] G. Ludwig, J. Chem. Phys. 25, 159 (1956).

[4] R. Livingston and H. Zeldes, J. Chem. Phys. 26, 351 (1957).

[5] K. Shimomura and N. Inoue, J. Phys. Soc. Japan 14, 86 (1959).

[6] F. Herlach, Helv. Phys. Acta 34, 305 (1961).

[7] N. W. Alcock, Acta Cryst. B 28, 2783 (1972).

[8] J. L. de Boer, F. van Bolhuis, R. Olthof-Hazekamp, and A. Vos, Acta Cryst. 21, 841 (1966).

[9] V. A. Shishkin, V. S. Grechishkin, T. G. Balicheva, G. A. Petrova and L. A. Cheburina, Izvest. Akad. Nauk SSSR., Ser. Fiz. 39, 2537 (1975).

[10] D. F. Baisa, A. I. Barabash, I. G. Vertegel, B. G. Vekhter, V. P. Zenchenko, and S. S. Stavrov, Khimicheskaya Fizika 3, 18 (1984).

[11] A. I. Barabash, T. A. Gavrilko, A. M. Petrosyan, G. A. Puchkovskaya, and A. N. Roshchin, Izvest. Akade. Nauk SSSR, Ser. Fiz. 55, 515 (1991).

[12] G. K. Semin, A. K. Moskalev, V. I. Pakhomov, E. M. Mikhailova, E. E. Vinogradov, and L. A. Azarova, Dokl. Adad. Nauk SSSR 211, 148 (1973).

[13] V. V. Iljukhin and V. R. Kalinin, Koord. Khimia 6, 1867 (1980).

[14] V. A. Shishkin, T. G. Balicheva, G. A. Petrova, A. G. Potapov, and L. A. Cheburina, J. Molec. Struct. 83, 349 (1982).

[15] R. Masse and J. C. Guitel, J. Sol. St. Chem. 32, 177 (1980).

[16] V. I. Vavilin, V. V. Iljukhin, and N. V. Belov, Dokl. Akad. Nauk SSSR 219, 1352 (1974).

[17] M. T. Averbuch-Pouchot, J. Sol. St. Chem. 41, 262 (1982).

[18] C. I. Cabello and E. J. Baran, Montah. Chem. 116, 591 (1985).

[19] A. M. Petrosyan, Yu. S. Bogachev, V. A. Shishkin, A. F. Volkov, and Yu. N. Venevtsev, Fizika i Khimia Tverdovo tela, Moskva 1978, p. 57.

[20] T. Okuda, H. Gotou, Y. Nishiyama, and A. Shimauchi, Science of light 26, 183 (1977).

[21] G. K. Semin, N. D. Gavrilova, D. L. Zagorskii, S. I. Kuznetsov, and V. K. Novik, Zhurn, Fiz. Khim. 61, 3111 (1987)! of $\mathrm{HIO}_{3}(\eta=0.5681)$ with an $\mathrm{IO}_{3}$ group, as a result of which the formerly equivalent $\mathrm{IO}_{3}$ groups become inequivalent. The hydrogen bond, and perhaps the $\mathrm{I}$... O bond as well distort this $\mathrm{IO}_{3}$ group, the asymmetry parameter of which increases up to 0.1751 . The NQR spectrum of En $\cdot 6 \mathrm{HIO}_{3}$, that consists of three lines on each transition, can be explained if we assume that there are two $\mathrm{IO}_{3}$ groups $(\eta=0.1332)$ which have given their protons to the ethylendiamine, together with which two $\mathrm{HIO}_{3}$ molecules form an equivalent hydrogen bonded grouping $(\eta=0.4542)$ and, at last two more $\mathrm{HIO}_{3}$ molecules from hydrogen bonds with $\mathrm{HIO}_{3}$ which in their turn are connected with $\mathrm{IO}_{3}$ groups. $\mathrm{IO}_{3} \ldots \mathrm{HIO}_{3} \ldots \mathrm{HIO}_{3}$ groupings are being formed from both sides of ethylendiammonium cation. The IR spectra [23] are in good agreement with such a description and correlate with NQR data.

[22] T. G. Balicheva and G. A. Petrova, Problemy sovrem. Khimii coord. soed. N4, 266 Leningrad 1974.

[23] A. M. Petrosyan, V. A. Shishkin, R. R. Anastasyan, and E. A. Hakopyan, Zhurn. neorg. khimii 35, 527 (1990).

[24] V. I. Vavilin, V. M. Ionov, V. V. Iljukhin, and N. V. Belov, Dokl. Akad. Nauk. SSSR 219, 1108 (1974).

[25] V. V. Iljukhin and V.I. Pakhomov, Coord. Khimia 3, 1892 (1977)

[26] A. M. Petrosyan, A. F. Volkov, V. A. Shishkin, and Yu. N. Venevtsev, Kristallografia 28, 915 (1983).

[27] N. I. Sorokina, A. A. Loshmanov, L. E. Fykin, and E. E. Ryder, Kristallografia 30, 895 (1985).

[28] A. M. Petrosyan, Kristallografia 29, 1024 (1984).

[29] A. M. Manotti Lanfredi, M. A. Pellinghelli, and A. Tiripicchio, Acta Cryst. B 28, 1822 (1972).

[30] F. Schellhaas, H. Hartl, and R. Frydrych, Acta Cryst. B 28, 2834 (1972).

[31] R. Frydrych, F. Schellhaas, and Ch. Pflugmacher, Z. Anorg. Allg. Chem. 399, 73 (1973).

[32] P. Lofgren, Acta Chem. Scand 21, 2181 (1967).

[33] K. Selte and A. Kjekshus, Acta Chem. Scand. 24, 1912 (1970).

[34] Y. D. Feikema and A. Vos, Acta Cryst. 20, 769 (1966).

[35] A. M. Petrosyan, A. F. Volkov, Yu. S. Bogachev, and Yu. N. Venevtsev, Zhurn. strukt. Khimii 20, 267 (1979).

[36] A. M. Petrosyan, A. F. Volkov, Yu. S. Bogachev, and Yu. N. Venevtsev, Abstracts of XII European Congress on Molecular Spectroscopy, Wroclaw Poland 1977, p. 345.

[37] A. M. Petrosyan, V. A Shishkin, and V. B., Gavalyan, Zhurn. neorg. Khimii 31, 57 (1986).

[38] A. M. Petrosyan and V. A Shishkin, Zhurn. neorg Khimii 31, 3178 (1986).

[39] A. M. Petrosyan, V. A Shishkin, and V. B. Gavalyan, Kristallografia 33, 1032 (1988).

[40] A. M. Petrosyan, V. A Shishkin, and V. B. Gavalyan, Kristallografia 33, 920 (1988).

[41] N. I. Sorokina, V. V. Iljukhin, and N. V. Belov, Dokl Akad. Nauk SSSR 236, 1361 (1977).

[42] A. F. Volkov, Radiospectroscopia, Perm 1979, p. 73.

[43] R. B. Creel, H. R. Broker, and R. G. Barnes, J. Magn. Reson. 41, 146 (1980).

[44] T. Yamaguchi, H. Suzuki, F. Shimizu, and Sh. Sawada, Jap. J. Appl. Phys. Pt. 1, 24, Suppl 2, 359 (1985). 